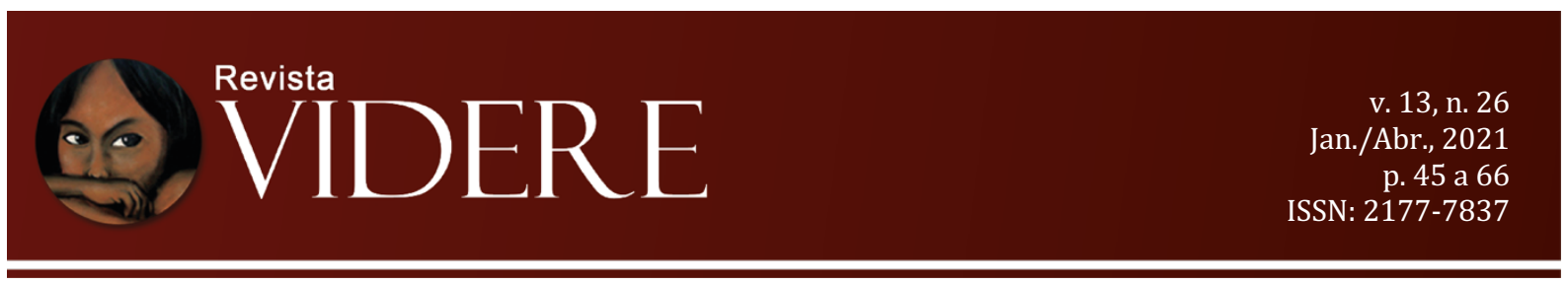

\title{
DOS DIREITOS INDÍGENAS NA AMÉRICA LATINA: O DESAFIO DA EFETIVAÇÃO
}

\author{
INDIGENOUS RIGHTS IN LATIN AMERICA: \\ THE CHALLENGE OF APPLICATION
}

\author{
SOBRE LOS DERECHOS INDÍGENAS EN AMÉRICA LATINA: \\ EL DESAFÍO DE LA EFICACIA
}

\begin{abstract}
Ricardo Oliveira Rotondano
Doutor em Direito pela Universidade Federal do Pará (UFPA). Docente da Universidade Estadual de Goiás (UEG) e do Centro Universitário Ritter dos Reis (UniRitter).

E-mail: rotondanor@gmail.com

OrcidID: https://orcid.org/0000-0002-8488-1620
\end{abstract}

Jane Felipe Beltrão

Antropóloga e historiadora, docente titular da Universidade Federal do Pará (UFPA), Campus Belém. Bolsista de produtividade em pesquisa do CNPq, nível $1 \mathrm{~B}$.

E-mail: janebeltrao@gmail.com OrcidID: https://orcid.org/0000-0003-2113-043X

Resumo: Nas últimas décadas, a América Latina tem se deparado com modificações jurídicas de significativo porte em suas Cartas Políticas, no que tange ao reconhecimento dos direitos indígenas. $\mathrm{O}$ novo constitucionalismo latino-americano, pautado pela afirmação de nações multiculturais dentro do Estado, detém estreita relação com este processo de transição. No entanto, as estruturas internas de poder permanecem vigentes, o que impede a consecução desses novos direitos reconhecidos. A atuação dos movimentos indígenas frente a instituições estatais nacionais e dentro dos organismos internacionais utilizando o discurso dos direitos humanos se revela como profícuo caminho para avançar em direção à efetivação dos direitos historicamente negados.

Palavras-chave: movimento indígena. novo constitucionalismo latino-americano. direitos humanos. relações de poder. judicialização de direitos.

Abstract: In recent decades, Latin America has been faced with legal changes of significant size in their Constitutions, regarding the recognition of indigenous rights. The new Latin American constitutionalism, guided by the statement of multicultural nations into the State, has a close relationship with this transitional process. However, the internal structures of power remain in effect, which avert the achievement of these newly recognized rights. The role of indigenous movements across the national state institutions and within the international 
organizations using the human rights speech is as fruitful way forward, towards the realization of the rights historically denied.

Keywords: indigenous movement. new Latin American constitutionalism. human rights. power relations. judicial ativism.

Resumen: En las últimas décadas, América Latina ha enfrentado importantes cambios legales en sus Cartas Políticas, en lo que respecta al reconocimiento de los derechos indígenas. El nuevo constitucionalismo latinoamericano, basado en la afirmación de naciones multiculturales dentro del Estado, tiene una estrecha relación con este proceso de transición. Sin embargo, las estructuras internas de poder permanecen vigentes, lo que impide la consecución de estos nuevos derechos reconocidos. La actuación de los movimientos indígenas en relación con las instituciones estatales nacionales y dentro de los organismos internacionales que utilizan el discurso de los derechos humanos se revela como una vía fructífera para avanzar hacia la realización de los derechos históricamente negados.

Palabras clave: movimiento indígena. nuevo constitucionalismo latinoamericano. derechos humanos. relaciones de poder. judicialización de derechos.

\section{Considerações iniciais}

A emergência do novo constitucionalismo no cenário latino-americano trouxe inegáveis avanços jurídico-políticos. O surgimento deste movimento de cunho libertário está associado à intensificação da organização dos povos indígenas nas últimas décadas do século $\mathrm{XX}$, que investiram em modelos de participação social e estratégias de luta política renovada dentro dos seus respectivos Estados. Fatores que contribuíram para a configuração de panorama extremamente favorável para que os direitos indígenas, recentemente positivados e ampliados, fossem devidamente aplicados pelos países da América Latina.

Apesar dos direitos formalmente conquistados pelos povos indígenas, tal projeção, entretanto, não se configurou em implementação efetiva da demanda dentro da sociedade brasileira e latino-americana. Até mesmo nos países que adotaram um modelo de cidadania plurinacional, combatendo a cidadania liberal e inscrevendo-o nas novas Constituições formuladas com a participação direta de comunidades indígenas, permanecem imersos em lutas políticas internas para alcançar a plenitude empírica dos dispositivos inscritos em lei. O objetivo do presente trabalho é analisar como o processo de positivação de direitos indígenas não se configurou em transição substancial da realidade fática enfrentada por tais povos.

Como pressuposto principal para a não consecução dos direitos reconhecidos pelos Estados aos povos indígenas, identifica-se a resistência imposta pelas estruturas de poder sociais ainda em vigor e a cooptação do Estado pelos setores socioeconômicos dominantes na 
sociedade. As relações de poder existentes dentro da sociedade e do Estado definem o direcionamento das políticas públicas e da implementação (ou não) de direitos, sendo cruciais para o entendimento da causa indígena no cenário latino-americano e igualmente no Brasil.

Por fim, o deslinde do presente trabalho versa sobre os possíveis caminhos e estratégias tomadas pelos povos indígenas para avançar em relação ao cumprimento dos seus direitos pelos Estados. Nesse quadro, a inserção dentro do âmbito de deliberação jurídicojudicial de instituições estatais e internacionais, utilizando o discurso dos direitos humanos como ferramenta na disputa travada pelo monopólio de dizer o direito (interpretação e aplicação) é alternativa essencial para combater as constantes violações dos direitos indígenas por parte de particulares e de instituições governamentais.

\section{Do conceito de nacionalidade latino-americana}

O qualificador nacionalidade, em tempos (pós-)modernos, define sumariamente os atributos gerais de determinados indivíduos e confere identidade nacional, segundo padrões e estereótipos edificados em cada país. Historicamente, a construção deste discurso teve importância singular dentro do assentamento territorial e desenvolvimento estrutural dos Estados nacionais, constituindo-se em embrião para os parâmetros do Estado contemporâneo. A intencionalidade unificadora da dialética nacionalista é fomentar o sentimento de pertença entre os sujeitos que habitam o mesmo espaço territorial, construindo sólidas bases organizativas institucionais por intermédio da criação do vínculo.

Como aduz Benedict Anderson (2008), a edificação da retórica do nacionalismo tem como meta primordial contribuir para a solidificação de uma unidade político-social em torno dos Estados modernos, via identificação recíproca dos indivíduos nacionais com a comunidade na qual coabitam. Porém, o esforço em prol da sedimentação do sentimento nacionalista acaba retirando do debate público as diferenças e os conflitos existentes entre as distintas identidades étnico-raciais presentes à comunidade cívica suprimidas que são pela suposta necessidade de reunir os cidadãos sob a égide do discurso homogeneizador.

A tentativa de construção de uma identidade nacional unívoca constitui-se em equívoco, ainda que mediante o apego à tradição e histórico comum do povo que coabita o mesmo território. Aliás, o referido histórico de tradições dos povos nacionais é pautado pela não linearidade das diferentes formações populacionais dos Estados modernos e remetem, de modo inexorável, a contribuições de etnias e culturas distintas dentro de um mesmo espaço (HALL, 2005). Entretanto, a hipotética pureza nacional, baseada em um percurso histórico 
ligado às tradições isoladas de caracteres externos de determinado povo, não existe; o que se verifica é o apagamento gradual da presença de certas culturas e etnias na construção idealizada daquela população nacional, realizando uma seleção do modelo identitário que se quer preservar.

A ocultação da pluralidade de identidades e culturas na seara nacional provoca, ainda, como efeito colateral, a invisibilização dos conflitos que permeiam aquelas sociedades formadas pela diferença. Dessa forma, as relações de conflito entre as diferentes raças e etnias nos Estados são, de modo direto, suprimidas por conta da relevância atribuída à construção de uma nacionalidade homogeneizada (BARBOSA, 2011). Os esforços que são direcionados para a uniformização da identidade nacional repercutem em uma conveniente pacificação ${ }^{1}$ das relações de embate entre raças e etnias, "harmonizando" conflitos interétnicos que deveriam ser evidenciados para que debatidos, fossem solucionados ou não.

$\mathrm{Na}$ América Latina, as recentes Constituições da Bolívia e do Equador propõem novas formas de abordagem do Estado nacional e da cidadania liberal edificadas no cenário global. A partir da construção do ideal de cidadania plural, que engloba o reconhecimento das diversas identidades culturais inseridas dentro do Estado, tais dispositivos ousam abrir espaço para as vozes que historicamente foram apagadas do processo de construção nacional em seus respectivos países. Cabe, dentro da seara de embate, atribuir especial enfoque para os povos indígenas como identidades etnicamente diferenciadas.

Apesar das Constituições Federais da Bolívia e do Equador serem as que se destacam no cenário latino-americano pelo arrojo e profundidade de suas propostas, as demais Cartas Políticas da América Latina também estão inseridas dentro de um contexto de mudança (COURTIS, 2009). É perceptível o advento de um movimento latino-americano pautado pelo constitucionalismo de caráter plural, oriundo da década de 1980, e que influenciou de forma contundente uma série de modificações no bojo das Constituições destes países, trazendo significativos avanços ao cenário dos direitos humanos (BELTRÃO; OLIVEIRA, 2014).

Como elementos que propiciaram a insurgência desta inovadora vertente políticojurídica, aponta-se: (1) o favorável cenário advindo da redemocratização dos países latinoamericanos, recém-libertos das suas respectivas ditaduras; (2) a crescente participação políticas dos agentes sociais até então subalternizados; (3) a extensão das mazelas advindas da política econômica global, pautada pelo capitalismo neoliberal, e (4) o desenvolvimento de sujeitos

\footnotetext{
${ }^{1}$ Usa-se a categoria pacificação a partir de SOUZA LIMA, Antonio Carlos. Um grande cerco de Paz: poder tutelar, indianidade e formação do Estado no Brasil. Petrópolis: Vozes, 1995.
} 
sociais como fonte de legitimação do locus sociopolítico e da constituição emergente de direitos às identidades coletivas (BELTRÃO; OLIVEIRA, 2014).

Dentro deste contexto no qual a contribuição destes elementos convergiu para a criação de novos institutos jurídicos plurais e anti-hegemônicos (SANTOS, 2003), caracterizase com propriedade uma valorização sem precedentes na contemporaneidade do empoderamento sociopolítico dos povos indígenas. A partir da tomada de consciência dos povos indígenas sobre a situação de opressão e exploração a qual estavam/estão submetidos, tais agrupamentos étnicos intensificaram o seu modelo organizativo em níveis estatais e mesmo supra-estatais, demandando necessidades a partir de novos instrumentos mais eficazes - o que inclui a sua inserção dentro dos quadros institucionais do Estado (AYLWIN, 2014).

José Aylwin (2014) reconhece, nesse processo de transição político-jurídica em direção à afirmação dos direitos indígenas com o advento do novo constitucionalismo latinoamericano, três fases principais. A primeira delas se configura com a adoção em 1989 da Convenção $\mathrm{n}^{\mathrm{o}} .169$ da Organização Internacional do Trabalho (OIT) referente aos Povos Indígenas e Tribais em Países Independentes. Após a edição da Convenção nº 169, advém a segunda fase deste ciclo: vários países adotaram em suas Cartas Políticas institutos normativos específicos destinados aos povos indígenas, reconhecendo uma gama de direitos pleiteados por tais coletivos - direcionados principalmente pela afirmação da sua autonomia em relação à terra, aos territórios, aos recursos naturais e à manutenção de preceitos culturais.

Apesar dos avanços no reconhecimento dos direitos dos povos indígenas, as medidas adotadas não se configuraram em uma efetiva transição do cenário regional de opressão das referidas coletividades. As modificações nas Cartas Políticas dos países da América Latina careceram de implementação, por diversas contingências, que indicam falta de ação dos organismos institucionais, influência do oligopólio empresarial internacional, entre outras possibilidades. Diante do cenário, os povos indígenas situados em diferentes localidades do continente acabaram tomando direcionamentos distintos - destaque para a tentativa, em alguns deles, de inserção dentro dos quadros políticos-representativos do Estado, através do engajamento pela disputa eleitoral nacional (GARCIA SERRANO, 2011).

A partir deste novo cenário, em que os povos indígenas ingressam nos postos diretivos de algumas nações, surge a terceira etapa deste ciclo sobre o qual José Aylwin (2014) discorre referindo à edição de novas Constituições na Bolívia e no Equador, pautadas de modo direto pelo constitucionalismo plurinacional. Aylwin (2014) destaca que, apesar das diferenças dos processos constitucionais dos dois países, ambos tiveram em comum a convocação de assembleia constituinte com representação dos povos indígenas. A conjuntura foi, 
evidentemente, propiciada pela participação ativa dos movimentos indígenas em seus respectivos Estados, que transformaram diretamente os cenários nacionais de ambos os países.

No Equador, deve-se conferir destaque para a atuação da Confederación de Nacionalidades Indígenas del Ecuador (CONAIE), de extrema relevância para a "promoção de ações de defesa das nacionalidades indígenas, ameaçadas pelas políticas de reestruturação econômica no país ao ampliar as fronteiras de exploração de minérios e de hidrocarbonetos nas suas regiões" (URQUIDI et al., 2008, p. 208). A partir da articulação com movimentos sociais urbanos, o CONAIE conseguiu a ampliação estatal dos direitos indígenas e o combate e desmonte de políticas de ajuste estrutural no governo equatoriano. Mais à frente, constituiu as bases populares que contribuíram para a eleição do presidente Rafael Correa em 2007, que iniciou o processo constituinte que originou a nova Constituição do Equador.

$\mathrm{Na}$ Bolívia, a atuação em massa dos novos movimentos sociais identitários nas décadas de 1970 e 80, sob o enfoque da valorização étnico-cultural indígena e da promoção de políticas públicas para as camadas historicamente subalternizadas, foram cruciais para a transição do paradigma nacional (GUIMARÃES, 2010). A partir do envolvimento direto dos movimentos sociais populares dentro do cenário de deliberação governamental - o que inclui, com propriedade, os indígenas - foi possível iniciar um processo de substituição da classe de poder do Estado boliviano (LINERA et al., 2010), culminando na eleição do líder indígena e cocaleiro Evo Morales e também na confecção de uma nova Carta Constitucional com viés marcadamente plurinacional.

É possível destacar uma série de avanços trazidos por esta terceira etapa do reconhecimento de direitos indígenas, proveniente das novas Cartas Políticas da Bolívia e do Equador. Por intermédio destas Constituições, de caráter claramente plurinacional, o conceito de nacionalidade liberal é dissolvido, dando-se prevalência para a diferença de identidades étnicas dentro do Estado - provocando a cisão, inclusive, com o discurso da superioridade ocidental eurocêntrica. Além disso, houve o reconhecimento da autonomia territorial e organizativa dos povos indígenas, valorizando-se as suas tradições, seus modos de vida e suas modalidades de resolução de conflitos.

\section{Entraves à consecução dos direitos indígenas}

O caso das demais nações latino-americanas não seguiu o exemplo da Bolívia e do Equador. As mudanças normativas constitucionais editadas ainda encontram dificuldades para serem implementadas. No caso do Brasil, há sinais de avanço em conjunto com pontos de 
retrocesso evidente. A demarcação de territórios indígenas no Brasil é significativo: dados apontam que até o início desta década, cerca de 672 terras indígenas haviam sido reconhecidas pelo Estado brasileiro (ATHIAS, 2011; D’AGOSTINO, 2013). Estes números representam cerca de $13 \%$ de toda a área territorial de um país com $8.515 .767,049 \mathrm{~km}^{2}$ de extensão (BRASIL, 2016) - estatística impressionante diante da população indígena, que representa 0,4\% do total de brasileiros que compreende 204.450.649 habitantes (BRASIL, 2015). Entretanto, constata-se ainda um significativo número de ações pendentes, versando sobre demarcação de terras indígenas, cujo julgamento não foi concluído (ALMEIDA, 2020).

Além disso, a maioria destas áreas demarcadas ainda se encontra sob tentativa de espoliação de garimpeiros, fazendeiros e do oligopólio empresarial nacional e multinacional (MILANEZ, 2015). A ambição de lucratividade mediante a exploração dos recursos naturais em grande escala, abundantes dentro das reservas e territórios indígenas provoca constantes conflitos entre grileiros e as comunidades indígenas, que em geral vitima estes últimos. O que impressiona é a atuação estatal em determinados casos, em que este é o agente diretamente interessado na intromissão dentro do território indígena (HOLSTON, 1991) - sob os mais diversos fundamentos: seja para construir estradas ou hidrelétricas e elevar a infraestrutura nacional, ou para explorar ou autorizar a exploração dos recursos renováveis e não renováveis existentes naquele território.

A atuação estatal parece ser o maior entrave à consecução plena dos direitos das comunidades indígenas pelo Estado brasileiro e pelas demais nações sul-americanas: o interesse econômico ante os recursos disponíveis nos territórios ocupados historicamente pelos índios. $\mathrm{O}$ próprio Estado, cooptado e manipulado pelos organismos mercadológicos nacionais e internacionais (SANTOS, 2013), opera neste sentido, propiciando bases institucionais de modo a viabilizar o desfrute das riquezas naturais assentadas em terras indígenas. No Brasil, podemos encontrar alguns casos e exemplos que ilustram este jogo espúrio de poder.

O primeiro deles se reflete na adoção de dispositivo constitucional claramente limitado no campo dos direitos acerca das terras indígenas. A questão da propriedade sobre tais territórios, definida pela Constituição Federal de 1988, foi decidida de forma a manter tal direito sob a tutela do Estado brasileiro que mantém a propriedade privada dos territórios indígenas como pertencente à União e concede apenas posse e usufruto aos indígenas ( $\mathrm{CF} / 88$, art. 20, XI). Tal opção normativa limita a autonomia e liberdade dos povos indígenas de realizarem o planejamento e fruição do seu espaço físico e natural de acordo com as suas necessidades e modos de vida (BELTRÃO; OLIVEIRA, 2014). 
Nesse sentido, os exemplos norte-americano e canadense, de atribuição do direito de propriedade privada coletiva aos povos indígenas sobre os territórios por estes ocupados historicamente se traduz em modelos a ser refletidos e implementados no Brasil. Estudos realizados nos referidos países demonstram a importância que a liberdade de autogestão dos indígenas sobre a terra e os seus recursos naturais tem na geração de renda e qualidade de vida desta etnia, que passam a deter o controle sobre os rumos efetivos da sua comunidade em relação ao seu ambiente (ANDERSON; PARKER, 2009). Além disso, a Corte Interamericana de Direitos Humanos já se pronunciou no sentido de que a negação da propriedade coletiva aos povos indígenas põe em evidente risco a integridade e a vida dos mesmos (CIDH, 2006).

Além da propriedade sobre a terra indígena, a Constituição Federal de 1988 elencou entre os bens da União os recursos minerais, inclusive no subsolo (CF/88, art. 20, IX), assim como lagos, rios e correntes de água em certas situações (CF/88, art. 20, III), nas quais os Estados são titulares dos recursos hídricos residuais (CF/88, art. 26, I). Mais adiante, a Constituição deixa claro que tais recursos são distintos da propriedade do território físico e que pertencem única e exclusivamente à União ( $\mathrm{CF} / 88$, art. 176), cabendo ao Congresso Nacional autorizar a exploração desses recursos nas terras indígenas (CF/88, art. 49, XVI). Os institutos elencados conduzem ao seguinte panorama: os indígenas são meros posseiros dentro dos territórios demarcados e homologados, no interior dos quais a União - proprietária das terras, segundo a Constituição Federal de 1988 - está legitimada a intervir e explorar os recursos minerais e hídricos existentes a qualquer tempo.

Há a previsão constitucional de oitiva das comunidades indígenas sobre possíveis intervenções em seus respectivos territórios, para o aproveitamento dos recursos minerais e hídricos $\left(\mathrm{CF} / 88\right.$, art. $\left.231, \S^{\circ}\right)$. Tal premissa está elencada ainda na Convenção $\mathrm{n}^{\circ} 169$ da Organização Internacional do Trabalho, em seu art. $6^{\circ}$, da qual o Brasil é signatário (Decreto 5.051, de 19 de abril de 2004). Entretanto, a aplicação deste preceito tem sido utilizada de modo meramente formal, pois a realização da consulta é regra a ser seguida, mas a decisão dos povos indígenas proveniente da consulta não vincula a atuação do Estado brasileiro (SCHETTINI, 2012).

O quadro reflete a ingerência dentro do espaço histórico de vivência dos indígenas que contraria a noção de autodeterminação propugnada pela Convenção $n^{\circ} 169$, que prevê estipular livremente o seu modelo de vida em relação ao ambiente histórica e espiritualmente ligado ao seu povo (CLAVERO, 2005). A modificação, ainda que parcial, no ambiente em que os indígenas coabitam, gera um rompimento incisivo em suas referências sócio-espaciais, 
provocando a perda de identificação com o produto histórico espacial, simbólico, político e cultural que é o território.

O segundo caso se refere ao contexto de subrepresentação institucional destes povos na América Latina, em que mesmo a presença considerável de indígenas na população total não se reflete em sua inserção dentro de quadros governamentais eletivos ou por nomeação (AYLWIN, 2014; GARCIA SERRANO, 2011). Assim como no Brasil, no Chile não há qualquer representante indígena nas duas casas do Congresso - sendo que $11 \%$ da população chilena é indígena. Na Guatemala, embora a população total seja $66 \%$ indígena dentro de um universo de aproximadamente 14,3 milhões de habitantes, estes contam apenas com 13\% do Congresso Nacional que possui 113 cadeiras. Apesar dos significativos esforços dos movimentos indígenas latino-americanos para a efetivação dos seus direitos (BICALHO, 2011), a tendência atual é de um rigoroso e duro enfrentamento com os setores de poder econômico-financeiros.

Mesmo os direitos anteriormente adquiridos encontram-se sob iminente risco de reformulação: o terceiro exemplo aqui citado é a discussão acerca da competência para a demarcação de territórios indígenas no Brasil. A Proposta de Emenda Constitucional $\mathrm{n}^{\mathbf{0}}$. 215/2000, de autoria do deputado federal Almir Moraes de Sá (PR/RR), prevê a transferência da competência para a demarcação e homologação dos territórios indígenas, atualmente do Poder Executivo, para o Poder Legislativo. Segundo Clovis Brighenti e Osmarina de Oliveira (2015), tal proposta representa sérios riscos à causa territorial indígena, tendo-se em conta a possível pressão exercida por setores empresariais - interessados nas terras indígenas e nos recursos nelas existentes - ante deputados e senadores que, com a aprovação da PEC 215, passariam a deter o controle das demarcações.

Não é novidade alguma discorrer sobre como os anseios privados dos sujeitos que ocupam os cargos institucionais do país prevalecem na seara política, em detrimento dos direitos da coletividade. A histórica junção entre o público e o privado no Brasil, consagrada na obra de Sérgio Buarque de Holanda (1995) - e sua tese sobre o homem cordial - esclarece, pois, como a manipulação de instrumentos estatais para o atendimento dos interesses particulares é elemento comum entre os brasileiros. O histórico das relações privadas e institucionais brasileiras está recheado de "coronéis" de diversos tipos em variadas searas, impondo-se mediante o poder financeiro e/ou político sobre os grupos vulnerabilizados e controlando os rumos do Estado para a satisfação dos seus propósitos (CARVALHO, 2014). Sem embargo, esta parece ser claramente a intenção subliminarmente contida na proposta da 
PEC 215, visando privilegiar a ambição de setores econômico-financeiros interessados nas terras indígenas e nos recursos delas provenientes.

É justamente dessa forma que se dá o embate em torno da regulação e efetivação dos direitos dos povos indígenas. É disputa desigual, em que comunidades indígenas e movimentos sociais enfrentam o oligopólio empresarial e os representantes governamentais por ele financiados. Dentre os setores que apresentam maior resistência às demandas das comunidades indígenas, está a bancada ruralista do Congresso Nacional, formada por donos de grandes propriedades agrárias no país. A vigorosa inserção desta camada econômica dentro das instituições representativas nacionais colabora com a cristalização das estruturas de poder social e economicamente vigentes, impedindo qualquer transformação social significativa (SIMIONATTO; COSTA, 2012) - inclusive no que tange às necessidades socioeconômicas pleiteadas pelos povos indígenas.

Estrutura esta que há muito se faz presente na sociedade brasileira. Os setores economicamente privilegiados da sociedade e, em especial, os grandes proprietários de terras gozaram historicamente de concessões e benesses estatais em grande monta. Os seus interesses se sobrepunham até mesmo às leis e às instituições responsáveis pela sua aplicação na sociedade. Nesse sentido, Sidney Chalhoub (2012) denuncia a ineficácia das leis que proibiam o tráfico de escravos africanos para o Brasil no século XIX, por conta dos interesses dos agricultores brasileiros na manutenção da referida prática. Constata-se que na atualidade, além dos grandes proprietários de terras, outros setores econômicos - como as mineradoras e as empreiteiras - continuam atuando politicamente de modo a frear a consecução dos direitos étnico-sociais, especialmente dos povos indígenas.

A disputa de diferentes grupos sociais em torno das suas demandas é um elemento inerente aos regimes democráticos. O grande mérito dos povos indígenas nas últimas décadas no cenário latino-americano foi repensar a sua organização coletiva e a sua atuação políticoinstitucional frente aos direitos pleiteados. Somado à favorável conjuntura advinda da redemocratização dos Estados sul-americanos, as comunidades indígenas alçaram importantes conquistas na seara jurídica e social, resultado da inserção mais vigorosa dentro dos meios decisórios políticos-institucionais - seja através de cargos eletivos ou da utilização de estruturas de participação pública.

Em Estados como a Bolívia e o Equador, tais conquistas foram vultosas - se comparadas às demais nações latino-americanas. Nesse sentido, os avanços obtidos nos países acima referidos devem servir de exemplo para as demais entidades estatais, no reconhecimento de direitos indígenas em maior escala. Entretanto, mesmo as referidas nações ainda possuem 
longo caminho a percorrer para a transição efetiva do contexto de subalternização histórica às quais estas comunidades foram submetidas. Além disso, mais do que a positivação de direitos, é necessário primar pela sua efetiva implementação (SIERRA, 2011), transformando a realidade empírica na qual os sujeitos em comento estão inseridos.

\section{Estratégias alternativas: utilização não-hegemônica e judicialização dos direitos sociais, econômicos e culturais}

Para as nações latino-americanas, alcançar o padrão de transformação jurídica e social desejado em relação aos povos indígenas é uma tarefa espinhosa. Especialmente para o Brasil, tal missão é dificultada pela pequena presença de indígenas em relação ao seu número total de habitantes - como já afirmado, o número de indígenas no Brasil representa $0,4 \%$ da população total do país que compreende 204.450.649 habitantes (BRASIL, 2015). Mesmo nos casos da Bolívia e Equador - países em que a população indígena se iguala ou supera o número de não indígenas (URQUIDI et al., 2008) - as inovações jurídicas não se converteram em transformações sociais drásticas, esbarrando nas relações de poder cristalizadas nas referidas sociedades nacionais.

Ante a evidente limitação, surge uma série de questionamentos: (1) como proceder para efetivar os direitos indígenas positivados em institutos jurídico-constitucionais pátrios e internacionais? (2) Quais as medidas que podem ser efetivamente tomadas pelos grupos reivindicatórios para que os seus direitos positivados não sejam violados ou mesmo retrocedam legalmente? (3) É possível enfrentar o conglomerado empresarial nacional e internacional que cooptou as forças estatais e realiza constantemente sucessivas tentativas de avançar sobre os territórios indígenas conquistados e os demais passíveis de demarcação e homologação governamental?

As instituições políticas que atuam na governança do Estado não são neutras, prevalecendo o interesse dos grupos hegemônicos que permanecem no poder inseridos dentro do quadro gerencial. Nega-se, de pronto, a visão do Estado como instituição isenta de opções políticas parciais, pautado em uma funcionalidade mecanicista de aplicação dos comandos legais ipsis literis. Os indivíduos que ocupam os cargos representativos dentro do cenário institucional detêm parâmetros políticos-ideológicos delimitados, direcionando o aparato estatal para o favorecimento de grupos e camadas sociais específicas.

Como produto da atividade estatal, o direito possui também um caráter dual, pois suas normas podem ser editadas e interpretadas para o atendimento de demandas libertárias ou 
conservadoras, a depender do processo de manipulação. A concepção da neutralidade jurídica e da sua aplicação mediante critérios estritamente técnicos responde, na verdade, a uma estratégia de manipulação ideológica que visa negar a possibilidade de questionamento das decisões jurídicas das instituições estatais, provocando a separação do campo decisional jurídico do debate público-participativo (BOURDIEU, 1989).

No momento em que tais concepções ilusórias são disseminadas no imaginário popular e alcançam o convencimento da população - de que o embate jurídico é estritamente técnico, do qual os particulares não detentores de tal saber ficam impedidos de participar - o objetivo das elites se consagra, há o afastamento da intervenção popular sobre esta área. Assim, a disputa pelo monopólio de definição e aplicação das normas jurídicas fica restrita ao poder político e econômico dentro do Estado (AZEVEDO, 2011), o que propicia a manutenção do status quo segregador e elitista.

Os movimentos sociais em torno das causas libertárias dentro da sociedade devem ter a ciência do jogo político inerente à manipulação dos institutos jurídicos. Enquanto as camadas populares se mantêm fora do debate político-jurídico, a aplicação da lei atenderá aos ditames do modelo capitalista exploratório e segregador imposto socialmente. Somente mediante a inserção dos grupos subalternizados - incluindo-se aqui os povos indígenas - no campo de disputa pela ampliação da interpretação e aplicação do direito, até então monopólio de poucos, é que os direitos diferenciados terão possibilidade efetiva de implementação.

Ante a apreensão deste ilusório estratagema de suposta imparcialidade do direito, os movimentos sociais emancipatórios poderão utilizar as ferramentas jurídicas para o atendimento de demandas, fazendo utilização não-hegemônica do direito (SANTOS, 2007). Os instrumentos normativos em vigência na contemporaneidade correspondem a um modelo liberal-burguês edificado econômica e politicamente (WOLKMER, 2003), centrado em valores ocidentais universalizados que de pronto dificulta a sua operacionalidade por setores excluídos. Entretanto, como instrumentos que podem ser direcionados para diferentes finalidades (VIANNA, 2008) - conservadora ou emancipatória - os direitos podem e devem ser manipulados pelos povos indígenas organizados em prol do atendimento de demandas históricas.

A intensificação dos esforços indígenas em torno das instâncias jurídico-institucionais tem crescido nas últimas décadas. Os movimentos indígenas têm transitado de uma atuação de fora para dentro do Estado, enfrentando o jogo político e manipulando os instrumentos de poder (GARCIA SERRANO, 2011). Não somente no contexto interno, mas sobretudo no plano internacional: a Convenção ${ }^{\circ} 169$ da OIT, de 1989, e a Declaração da Organização das Nações 
Unidas sobre os Direitos dos Povos Indígenas, de 2007, são importantes conquistas no referido contexto (BURGER, 2014). A adoção destes marcos de cunho declaratório e normativo vem no sentido de provocar a transição a uma política assimilacionista, anteriormente aplicada, de base evidentemente colonial, a partir da argumentação de que seria benéfico para os povos indígenas adotar os valores e modos de vida compartilhados pela sociedade dominante, em direção à autodeterminação que implica na gestão de seus próprios destinos.

Na década de 1980, houve a criação do Grupo de Trabalho para Povos Indígenas ${ }^{2}$ como órgão interno da $\mathrm{ONU}$, incumbido de tratar especificamente da problemática de violação dos direitos indígenas nos países-membros. Ademais, as populações indígenas se fizeram representar com delegações específicas na Conferência Mundial sobre Meio Ambiente e Desenvolvimento, ocorrida no Rio de Janeiro em 1992, e na Conferência Mundial de Direitos Humanos, realizada em Viena no ano de 1993, garantindo sua voz nos espaços de negociação internacional (BURGER, 2014).

Além da inserção dentro de quadros políticos e de encontros de lideranças globais da Organização das Nações Unidas, os povos indígenas têm investido nas demandas jurídicas frente às cortes de justiça internacionais. No cenário latino-americano, destacamos a verificação de pleitos indígenas direcionados à Corte Interamericana de Direitos Humanos, sob os mais diferentes aspectos: a defesa dos seus caracteres culturais, o direito ao território, a não intervenção Estatal em seus assuntos internos e modos de vida, entre outras tantas demandas (ESTUPIÑAN SILVA; IBÁÑEZ RIVAS, 2014).

O recente movimento de direcionamento de litígios sobre os direitos sociais, econômicos e culturais pelos povos indígenas - e por outros grupos vulnerabilizados - tem como principal fundamento a não efetivação destes direitos pelos setores institucionais responsáveis (ABRAMOVICH; PAUTASSI, 2010). Outros fatores contribuíram igualmente para a propagação da mudança de perspectiva; é o caso da crescente constitucionalização de tais direitos nos países latino-americanos e a organização e mobilização da sociedade civil, em especial dos movimentos sociais (LANGFORD, 2009).

Por certo, muitas críticas têm sido opostas à judicialização dos direitos sociais, econômicos e sociais. As principais delas se referem à uma indevida intromissão do judiciário em pautas eminentemente políticas, que exigem o planejamento político, configurando uma ofensa à separação de poderes estatais. Entretanto, a plausibilidade de tais justificativas cai por terra ante a evidente debilidade das instituições políticas responsáveis pela implementação

\footnotetext{
${ }^{2}$ O Grupo de Trabalho para Povos Indígenas foi extinto no ano de 2006, por conta de uma reforma no sistema de direitos humanos da Organização das Nações Unidas.
} 
destes direitos que, por não cumprirem devidamente a sua função, veem transferidas para a esfera judicial a legitimação para tanto (ABRAMOVICH, 2005). Desse modo, mais do que uma demanda, a justiciabilidade de direitos sociais, econômicos e culturais é uma realidade - sendo exercida por tribunais nacionais e internacionais.

No processo de análise dos litígios indígenas, a Corte Interamericana tem se pautado por uma metodologia de análise com menor rigor formalista, adotando uma maior maleabilidade jurídica inerente à ponderação acerca de casos com características culturais diferenciadas do modo de vida ocidental moderno. Segundo Estupiñan Silva e Ibáñez Rivas (2014, p. 294), este modelo inovador visa uma adaptação aos elementos histórico-axiológicos das comunidades indígenas, e "consiste em interpretar o direito aplicável no contexto e em estreita relação com a realidade do peticionário".

A pretensão desta nova metodologia jurídico-decisional é de incorporar ao campo de interpretação e aplicação jurídicas elementos externos à legislação positivada e formalista, como o direito consuetudinário dos povos indígenas - que, por certo, pré-existe ao direito dogmático-constitucional e internacional contemporâneos. Tal abertura jurídica não se desvinculada de pactos e documentos universais de direitos humanos firmados na seara internacional - que se coaduna com estes, na medida em que busca novas formas de solução de litígios que respeitem os modos de vida e as particularidades de cada povo (ESTUPIÑAN SILVA; IBÁÑEZ RIVAS, 2014).

Entretanto, mais do que a incorporação de elementos consuetudinários indígenas em uma ordem ocidental pré-constituída, urge o reconhecimento dos ordenamentos jurídicos indígenas como normas e instituições plenamente aptas para a organização do seu modo de vida autônomo. O reclame, dessa forma, é por um rompimento estratégico com a política de gerenciamento ocidental das instituições indígenas - com viés claramente colonial - para que os direitos frutos da auto-organização destes povos possam ser efetivados pelos seus próprios membros. Como sistemas jurídicos autônomos e independentes do direito estatal positivado, os direitos dos povos indígenas interpelam o Estado para que sua eficácia não seja prejudicada por intervenções autoritárias e paternalistas da comunidade ocidental (SIERRA, 2011).

O reconhecimento de uma ordem jurídica historicamente edificada, que precede a formação e organização dos modelos modernos de sociedade, tem um forte viés anticolonial, de negação da imposição da forma de direito positivada e estatalmente confeccionada como unicamente aceita e válida. Recorrer às teses do pluralismo jurídico, dessa forma, não visa diminuir o direito monista estatal e nem sequer negar a sua eficácia; busca, segundo a lição de 
Antonio Carlos Wolkmer (2001), confirmar a legitimidade de outras ordens jurídicas que não são emanadas diretamente e exclusivamente do Estado, como o direito indígena.

Impelir os representantes governamentais dos Estados nacionais a adotar medidas para a implementação de elementos pluralistas e multiculturais nas suas instituições políticas, reconhecendo a autodeterminação das quais devem gozar os povos indígenas ainda é um imenso desafio. A afirmação da capacidade de autogoverno e da jurisdição efetivamente indígena, dentro das quais possa haver a liberdade de tomada de decisão institucional e o pertinente solução de demandas pelas próprias etnias, são preceitos-chave nesta tarefa. Para tanto, tais atributos decisionais devem ser horizontalmente equiparados às instituições nacionais - não meramente subordinadas a elas, sob pena de que o direito ao autogoverno se transforme num elemento indígena ilusório e incompleto (KYMLICKA, 1995).

Os esforços dos movimentos indígenas estão coerentemente direcionados para a atuação frente aos tribunais nacionais e internacionais, movimentando as instituições judiciais para alcançar a consecução das suas demandas (SIERRA, 2011) Ao contrário de parte dos países sul-americanos, nos quais os povos indígenas são quantitativamente suficientes para angariar substancial representação político-institucional, no Brasil a minoria numérica de pessoas indígenas impõem outras alternativas - a luta no campo de interpretação e aplicação do direito, dentro das instâncias judiciais, é um deles. A partir da formação de alianças com outros movimentos sociais emancipatórios, aliada com a intensificação da participação no espaço de debate político-judiciário nacional e também internacional, os direitos dos povos indígenas no Brasil encontram caminhos promissores para sua implementação.

\section{Do horizonte futuro}

Nas últimas décadas, mudanças relevantes na seara dos direitos indígenas irromperam nos países da América Latina. A intensificação da atuação indígena em relação às demandas pelos seus direitos historicamente negados, em movimentos somados aos demais movimentos sociais e étnicos subalternizados e instituições de defesa dos direitos humanos configuraram cenário propício à conquista estratégica do reconhecimento institucional de demandas específicas. Paulatinamente, houve a inserção de institutos legais ampliados sobre direitos indígenas nas Constituições dos Estados latino-americanos no final do século passado, em maior ou em menor grau.

Entre os países latino-americanos, houve a eclosão de movimentos indígenas em maior proporção na Bolívia e no Equador - países em que a população indígena equivale ou mesmo 
supera os demais grupos étnico-raciais. A maior intensidade da atuação indígena nestes Estados e o investimento na ocupação de postos institucionais eletivos pelos indígenas geraram um processo de edição até mesmo de novas Cartas Políticas, tendo tanto o Equador como a Bolívia editado novas Constituições. Dentro de cada um dos processos constituintes, foi garantida a plena participação dos povos indígenas na elaboração das normas constitucionais que entraram em vigor.

O surgimento do movimento jurídico-político do novo constitucionalismo latinoamericano, pautado por elementos plurinacionais - de negação de uma nacionalidade una dentro dos Estados e de valorização de diferenças étnico-culturais - realizou transições legais relevantes e trouxe diversas conquistas no plano empírico. Entretanto, o quadro de opressão dos povos indígenas nestes países ainda persiste: as estruturas de poder cristalizadas dentro dos Estados nacionais permanecem, com o oligopólio empresarial ditando as principais políticas dos países, impedindo a plena consecução dos direitos indígenas.

A retórica colonial disseminada socialmente confere feições discriminatórias aos povos indígenas, opondo seus pleitos aos anseios dos grupos populares manipulados por esse discurso simbólico fortemente nacionalista e integracionista. As terras e os recursos existentes nos territórios indígenas ainda são vislumbrados por grande parte da população brasileira como pertencentes ao país - os indivíduos creem que deva ser conferida destinação produtiva nos moldes capitalistas e exploratórios a tais bens, contribuindo para a geração de riquezas do país.

Tais fatores contribuem para a imposição de barreiras à plena aquisição e fruição pelos indígenas dos territórios e recursos que lhes foram historicamente subtraídos, e que lhes pertencem de modo integral e sem reservas por direito. Os dispositivos constitucionais que regulam os direitos indígenas sobre os seus territórios ainda atribuem a sua propriedade ao Estado, conferindo-lhe além disso a possibilidade de intervenção para efetivar a exploração de recursos minerais e hídricos - como é o caso brasileiro. A possibilidade de negativa dos povos indígenas acerca desta intromissão estatal é bastante limitada, na qual possíveis consultas aos habitantes destes territórios não são vinculantes aos direitos originários.

Ante o problema de efetividade de direitos exposta, os movimentos indígenas têm se voltado recentemente para a inserção dentro das instituições do Estado responsáveis pela interpretação e aplicação do direito, colocando suas demandas étnico-sociais na forma do discurso de direitos fundamentais e humanos negados. Tal estratégia põe em evidência a dupla utilização dos institutos jurídicos, que podem servir tanto para legitimar a ordem posta quanto para a sua transformação. Amparados pelo discurso jurídico dos direitos positivados, 
propugnam a devida efetivação pelos entes estatais - que, em geral, atuam também como violadores de tais direitos em determinados casos.

A utilização contra-hegemônica dos direitos, como caminho para impelir ao Estado e aos particulares ao reconhecimento de demandas históricas, tem sido realizada tanto em sede nacional como internacional. A Corte Interamericana de Direitos Humanos, aliás, tem tomado postura ativa na defesa dos direitos indígenas dentro do continente, na qual as denúncias de violações contra os direitos indígenas têm sido acolhidas e analisadas levando-se em consideração não somente os direitos positivados, mas igualmente os sistemas jurídicos que extrapolam a atuação do Estado - como os direitos consuetudinários dos próprios povos indígenas.

O direcionamento dos pleitos indígenas pela efetivação dos seus direitos para instituições político-jurídicas na seara nacional e internacional, utilizando-se do discurso dos direitos fundamentais e humanos, reveste-se como estratégia indispensável para a defesa do seu território e respeito aos seus modos de vida. A atuação somente em esferas não estatais - que durante muito tempo foi o principal campo de atuação dos movimentos étnicos e sociais permite o Estado como campo aberto para a cooptação do capitalismo organizado, que passa a manipular as instituições para o atendimento dos interesses privados.

Reconhecendo a importância da atuação por fora do Estado - como em organismos de educação não formal, voltados para a ampliação da compreensão da questão indígena - há que se ressaltar que a inserção também deste movimento de pleito por direitos é de crucial relevância. Adentrar o espaço pela deliberação acerca da interpretação e aplicação do direito é, para o movimento indígena, tarefa imprescindível para modificar o paradigma hegemônico de exploração do seu território e subalternização colonial do seu modo de vida. Apoderar-se do discurso dos direitos humanos, manejando-o em instituições político-jurídicas nacionais e internacionais, instrumentaliza a luta indígena com poderosas ferramentas de embate frente às oligarquias coloniais estabelecidas nos países subalternizados, consolidando o conquistado e arregimentando estratégias para novos embates.

\section{Referências}

ABRAMOVICH, Victor; PAUTASSI, Laura. La medicion de derechos en las políticas sociales. Buenos Aires: Del Puerto, 2010. 
ABRAMOVICH, Victor. E. Linhas de trabalho em direitos econômicos, sociais e culturais: instrumentos e aliados. SUR - Revista Internacional de Direitos Humanos, n. 2, pp. 188$223,2005$.

ALMEIDA, Eloísa Machado de (coord.); GUIMARÃES, Lívia Gil; FERRARO, Luíza Pavan. Agenda dos direitos socioambientais no Supremo Tribunal Federal. São Paulo: FGV Direito SP, 2020.

ANDERSON, Benedict. Comunidades imaginadas. São Paulo: Companhia das Letras, 2008. ANDERSON, T. L.; PARKER, D. P.. Economic development lessons from and for Northamerican Indian economies. The Australian Journal of Agricultural and Resource Economics, n. 53, pp. 105-127, 2009.

ATHIAS, Renato Monteiro. Os serviços de saúde e as populações indígenas. Revista Coletiva, n. 3, jan./mar. 2011.

AYLWIN, José. Los derechos de los pueblos indígenas en América Latina: avances jurídicos y brechas de implementación. In BELTRÃO Jane Felipe; BRITO FILHO, Jose Claudio Monteiro de; GÓMEZ, Itziar; PAJARES, Emilio; PAREDES, Felipe; ZÚÑIGA, Yanira (Coords.). Derechos humanos de los grupos vulnerables, 2014, pp. 285-314.

AZEVEDO, Rodrigo Ghiringhelli de. A força do direito e a violência das formas jurídicas. Revista de Sociologia e Política, v. 19, n. 40, pp. 27-41, out. 2011.

BARBOSA, Márcia Fagundes. Nação, um discurso simbólico da modernidade. Crítica Cultural, Palhoça, SC, v. 6, n. 1, pp. 203-216, jan./jun. 2011.

BELTRÃO, Jane Felipe; OLIVEIRA, Assis da Costa. Movimentos, povos \& cidadanias indígenas: inscrições constitucionais e direitos étnicos na América Latina. In BELTRÃO Jane Felipe; BRITO FILHO, Jose Claudio Monteiro de; GÓMEZ, Itziar; PAJARES, Emilio; PAREDES, Felipe; ZÚÑIGA, Yanira (Coords.). Derechos humanos de los grupos vulnerables, 2014, pp. 251-284.

BICALHO, Poliene S. S.. Protagonismo indígena no Brasil: movimento, cidadania e direitos (1970-2009). Anais do XXVI Simpósio Nacional de História - ANPUH, São Paulo, jul. 2011. BOURDIEU, Pierre. O poder simbólico. Trad. Fernando Tomaz. Rio de Janeiro: Bertrand Brasil, 1989.

BRASIL. Resolução n. 2, de 21 de junho de 2016. Diário Oficial da União, n. 118, Poder Executivo, Brasília, DF, 22 jun. 2016. Seção 1, p. 87.

BRASIL. Resolução n. 4, de 26 de agosto de 2015. Diário Oficial da União, n. 165, Poder Executivo, Brasília, DF, 28 ago. 2015. Seção 1, p. 98. 
BRIGHENTI, Clovis A.; OLIVEIRA, Osmarina de. PEC 215: ameaça aos direitos dos povos indígenas, quilombolas e meio ambiente. 2. ed. Florianópolis: CIMI, 2015.

BURGER, Julian. La protección de los pueblos indígenas en el sistema internacional. In BELTRÃO Jane Felipe; BRITO FILHO, Jose Claudio Monteiro de; GÓMEZ, Itziar; PAJARES, Emilio; PAREDES, Felipe; ZÚÑIGA, Yanira (Coords.). Derechos humanos de los grupos vulnerables, 2014, pp. 220-250.

CARVALHO, José Murilo de. Cidadania no Brasil: o longo caminho. 18. ed. Rio de Janeiro: Civilização Brasileira, 2014.

CHALHOUB, Sidney. A força da escravidão: ilegalidade e costume no Brasil oitocentista. São Paulo: Companhia das Letras, 2012.

CLAVERO, Bartolomé. The indigenous rights of participation and international development policies. Arizona Journal of International and Comparative Law, Tucson, AZ, v. 22, n. 1, pp. 41-51, 2005.

CORTE INTERAMERICANA DE DIREITOS HUMANOS, caso Comunidad indígena Sawhoyamaxa vs Paraguay. Sentença de Mérito, Reparações e Custas, 29 de março de 2006. COURTIS, Christian. Anotações sobre a aplicação da Convenção 169 da OIT sobre povos indígenas por tribunais da América Latina. SUR - Revista Internacional de Direitos Humanos, n. 10, pp. 53-81, jun. 2009.

D’AGOSTINO, Rosanne. Brasil tem 672 terras indígenas; entenda como funciona demarcação. Portal G1, São Paulo, jun. 2013.

ESTUPIÑAN SILVA, Rosmerlin; IBÁÑEZ RIVAS, Juana María. La jurisprudencia de la Corte Interamericana de Derechos Humanos en materia de pueblos indígenas y tribales. In BELTRÃO Jane Felipe; BRITO FILHO, Jose Claudio Monteiro de; GÓMEZ, Itziar; PAJARES, Emilio; PAREDES, Felipe; ZÚÑIGA, Yanira (Coords.). Derechos humanos de los grupos vulnerables, 2014, pp. 316-356.

GARCIA SERRANO, Fernando. La participación política del movimento indígena ecuatoriano; balance crítico (1990-2007). In CHENAUT, Victoria; GÓMEZ, Magdalena; ORTIZ, Héctor; SIERRA, María Teresa (Coords.). Justicia y Diversidad en América Latina. Pueblos indígenas ante la globalización. México/Ecuador, Ciesas/Flacso, La Casa Chata, 2011, pp. 219-235.

GUIMARÃES, Alice Soares. A reemergência de identidades étnicas na modernidade: movimentos sociais e Estado na Bolívia contemporânea. 2010. 437 f.. Tese (Doutorado em Sociologia) - Faculdade de Ciências Humanas, Universidade Estadual do Rio de Janeiro, Rio de Janeiro, 2010. 
HALL, Stuart. A identidade cultural na pós-modernidade. Trad. Tomaz Tadeu da Silva; Guacira Lopes Louro. Rio de Janeiro: DP\&A, 2005.

HOLANDA, Sérgio Buarque de. Raízes do Brasil. 26. ed. São Paulo: Companhia das Letras, 1995.

HOLSTON, James. The misrule of law: land and usurpation in Brazil. Comparative Studies in Society and History, n. 33, v. 4, pp. 695-725, 1991.

KYMLICKA, Will. Ciudadanía multicultural. Barcelona: Paidós, 1995.

LANGFORD, Malcolm. Judicialização dos direitos econômicos, sociais e culturais no âmbito nacional: uma análise socio-jurídica. SUR - Revista Internacional de Direitos Humanos, n. 11, pp. 99-133, dez. 2009.

LINERA, Álvaro Garcia; PRADA, Raúl; TAPIA, Luis; CAMACHO, Oscar Vega. Eı Estado: campo de lucha. La Paz: Muela del Diablo, 2010.

MILANEZ, Felipe. Grilagem de terra e saque de recursos: a máquina de matar na Amazônia.

Carta Capital, 24 mai. 2015.

SANTOS, Boaventura de Sousa. Direitos humanos, democracia e desenvolvimento. São Paulo: Cortez, 2013.

SANTOS, Boaventura de Sousa. Poderá o direito ser emancipatório? Revista Crítica de Ciências Sociais, n. 65, pp. 3-76, mai. 2003.

SANTOS, Boaventura de Sousa. Renovar a teoria crítica e reinventar a emancipação social. Tradução: Mouzar Benedito. São Paulo: Boitempo, 2007.

SCHETTINI, Andrea. Por um novo paradigma de proteção dos direitos dos povos indígenas: uma análise crítica dos parâmetros estabelecidos pela Corte Interamericana de Direitos Humanos. SUR - Revista Internacional de Direitos Humanos, v. 9, n. 17, pp. 63-85, dez. 2012.

SIERRA, María Teresa. Pluralismo jurídico e interlegalidad. Debates antropológicos en torno al derecho indígena y las políticas de reconhecimento. In CHENAUT, Victoria; GÓMEZ, Magdalena; ORTIZ, Héctor; SIERRA, María Teresa (Coords.). Justicia y Diversidad en América Latina. Pueblos indígenas ante la globalización. México/Ecuador, Ciesas/Flacso, La Casa Chata, 2011, pp. 385-406.

SIMIONATTO, Ivete; COSTA, Carolina Rodrigues. Como os dominantes dominam: o caso da bancada ruralista. Temporalis, Brasília, ano 12, n. 24, pp. 215-237, jul./dez. 2012.

SOUZA LIMA, Antonio Carlos. Um grande cerco de Paz: poder tutelar, indianidade e formação do Estado no Brasil. Petrópolis: Vozes, 1995.

URQUIDI, V.; TEIXEIRA, V.; LANA, E.. Questão indígena na América latina: direito internacional, novo constitucionalismo e organização dos movimentos indígenas. Cadernos PROLAM/USP, ano 8, v. 1, pp. 199-222, 2008. 
VIANNA, Túlio Lima. Teoria quântica do direito: o direito como instrumento de dominação e resistência. Prisma Jurídico, São Paulo, v. 7, n. 1, pp. 109-129, jan./jun. 2008.

WOLKMER, Antonio Carlos. Ideologia, Estado e direito. 4. ed. São Paulo: Editora Revista dos Tribunais, 2003.

WOLKMER, Antonio Carlos. Pluralismo jurídico: fundamentos de uma nova cultura no direito. 3. ed. São Paulo: Alfa Omega, 2001. 